\title{
TACE performed in patients with a single nodule of Hepatocellular Carcinoma
}

\author{
Eleonora Terzi ${ }^{1}$, Fabio Piscaglia ${ }^{1 *}$, Ludovica Forlani ${ }^{2}$, Cristina Mosconi ${ }^{2}$, Matteo Renzulli ${ }^{2}$, Luigi Bolondi ${ }^{1}$, Rita Golfieri ${ }^{2}$ \\ and BLOG-Bologna Liver Oncology Group, S.Orsola-Malpighi Hospital, University of Bologna, Bologna, Italy
}

\begin{abstract}
Background: Patients with single hepatocellular carcinoma (HCC) usually undergo transarterial chemoembolization (TACE) if they are not candidates for curative surgical or ablative therapy. The primary aim of the study was to assess the overall survival and clinical determinants of survival in patients with single HCC who underwent TACE. The secondary aims were tumor response, local and distant recurrence rates, time to recurrence and the impact of TACE on liver function.
\end{abstract}

Methods: The outcomes of 148 consecutive patients with single HCC who underwent TACE from January 2004 to December 2009 were retrospectively analyzed.

Results: Complete response (CR) was observed in 95/148 (64\%) patients and a partial response (PR) in 39 (26\%) patients. The recurrence rate was $27 \%, 42 \%$ and $65 \%$ at 6,12 and 24 months, respectively. The day after TACE, 56 (38\%) patients had a Child-Pugh increase $\geq 1$ and 93 (63\%) had a MELD increase $\geq 1$. Median survival was 36.0 months with 1-, 3- and 5 -year survival rates of $85 \%, 50 \%$ and $26 \%$, respectively. Bland portal thrombosis was not seen to have any impact at univariate survival analysis; however, a slight impairment of PS (PS-1) in small tumors had some, although minor, impact on prognosis. Factors associated with shorter survival at multivariate analysis were tumor $>5 \mathrm{~cm}$, absence of $\mathrm{CR}$, ascites, alpha-fetoprotein (AFP) $\geq 14.5 \mathrm{ng} / \mathrm{mL}$ and a MELD increase $\geq 1$.

Conclusions: Transarterial chemoembolization is a valid treatment option in patients with single HCC not suitable for curative treatment. Bland PVT has no major impact on survival and a slight impairment of PS attributable to cirrhosis in patients within the Milan criteria should not preclude the use of TACE.

Keywords: Hepatocellular carcinoma, Transarterial chemoembolization, Tumor radiological response

\section{Background}

Curative treatment is considered the first choice treatment for patients with single hepatocellular carcinoma (HCC) according to the international guidelines [1]. In particular, liver transplant (LT) is recommended in patients within the Milan criteria (MC) [2], and surgical resection or ablation in patients not suitable for LT [3]. In clinical practice, however, patients with a single tumor unsuitable for curative treatment are usually treated with transarterial chemoembolization (TACE) on the basis of a clinical judgment. In fact, according to the "stage migration" concept, patients who cannot receive the

\footnotetext{
*Correspondence: fabio.piscaglia@unibo.it

'Division of Internal Medicine, Department of Digestive Disease and Internal Medicine, Sant'Orsola-Malpighi Hospital, University of Bologna, Via Albertoni 15, 40138 Bologna, Italy

Full list of author information is available at the end of the article
}

recommended treatment allocation within their stage should be offered treatment with the next most suitable option within the same stage or the next stage [1]. Transarterial chemoembolization is a well-established treatment for HCC and the current guidelines recommend TACE as a first line non-curative treatment for intermediate stage patients with multinodular asymptomatic tumors without vascular invasion or extrahepatic spread [1]. Nonetheless, the percentage of patients with single HCC who routinely underwent TACE is higher than $40 \%$ in many studies [4-6].

The primary endpoint of the present study was to evaluate the overall survival and clinical determinants of survival, including the presence of bland portal vein thrombosis (PVT) and slight impairment of performance status (PS), in patients with a single nodule of HCC who 
underwent TACE and could not undergo curative treatment.

The secondary end points were tumor response at 1 month, local and distant recurrence rates, time to recurrence and impact of TACE on liver function.

\section{Patients and methods Patient population}

The present retrospective analysis was based on a database of 902 consecutive patients who underwent TACE as a first line treatment between January 2004 and December 2009 in the Interventional Radiology Unit of Sant'OrsolaMalpighi Hospital in Bologna after a multidisciplinary team (MDT) discussion. The analysis of the follow-up was closed in May 2012 in order to have at least 30 months of follow-up for each patient. The inclusion criteria for enrollment in the study was: (1) diagnosis of single HCC according to the European Association for the Study of the Liver/American Assoication for the Study of Liver Diseases (EASL/AASLD) criteria [7,8]; (2) Child-PughTurcotte (CPT) hepatic function A or B; (3) PS 0 or 1 and (4) first conventional TACE performed between January 2004 and December 2009. The exclusion criteria were: (1) the absence of at least one imaging control (CT: Computed Tomography and/or MRI: Magnetic Resonance Imaging) before and after TACE treatment; (2) multiple HCC nodules; (3) portal branch/hepatic vein tumor invasion or extrahepatic spread (4) Child-Pugh hepatic function C; (5) PS $\geq 2$; (6) previous treatment for HCC and (7) non-conventional TACE treatment (DC-Beads, mixed treatments or radioembolization).

Portal vein thrombosis was considered to be bland or neoplastic based on definite criteria previously reported by our group [9].

In the series of consecutive patients, one hundred and forty-eight patients fulfilled the inclusion criteria, and were therefore selected as the cohort for the study (Figure 1).

The study protocol complied with the provision of the Good Clinical Practice guidelines and the Declaration of Helsinki and was approved by the Institutional Review Board S.Orsola-Malpighi hospital. Collection of informed consents was waived given the retrospective nature of the study.

\section{Methods}

\section{TACE protocol and technical procedure}

In our clinical practice, HCC treatment for patients with single HCC follows the BCLC staging system [10] but each case is discussed in MDT meetings and individually tailored, according to the considerations recently included in the recommendations of the Italian Association for the Study of the Liver [11].

Transarterial chemoembolization treatment was performed in single nodules if curative treatment was not

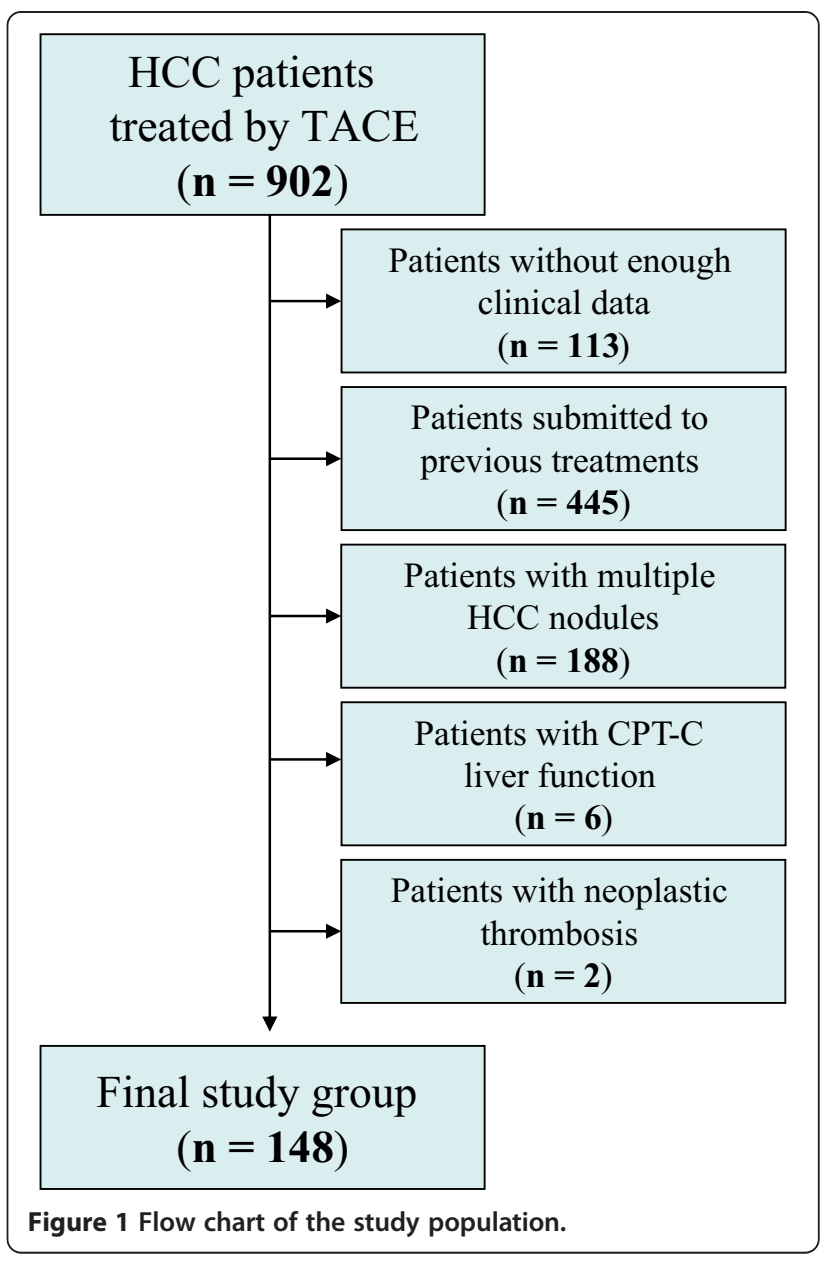

feasible due to tumor size, tumor location, technical applicability of treatment, severity of liver dysfunction, presence of portal hypertension, presence of comorbidities and their severity, and individual consent for specific treatment.

Before treatment, baseline clinical evaluation, laboratory tests, chest X-ray and tumor stage were assessed in all patients. Very few patients underwent TACE despite a CPT function of B8-B9, which usually contraindicates TACE due to the risk of irreversible terminal liver failure. Those patients were treated because they were on the waiting list for liver transplantation and they could undergo salvage liver transplantation in case of liver failure. At admission, daily living abilities were assessed and PS was calculated [12]. According to the guidelines [1], all patients with compromised abilities (PS 1) were classified as being into advanced tumor stage (BCLC-C) irrespective of their origin (given the extreme difficulty and subjectivity to ascribe such complaints either to the underlying cirrhosis or to the occurrence of cancer).

Conventional TACE was carried out by selective catheterization of the hepatic arteries feeding the lesions; in the majority of patients, superselective or 
selective TACE was carried out using a highly flexible coaxial microcatheter (2.7-2.8 Fr Progreat ${ }^{\mathrm{TM}}$ Terumo or Renegade $^{\mathrm{TM}} \mathrm{Hi}$-flo Boston Scientific) passed through a 4Fr catheter previously placed in the hepatic artery. For selective transarterial chemoembolization, the tip of the microcatheter was placed into the hepatic arterial branch afferent to the segment where the tumor was located. In superselective TACE, the tip of the catheter was additionally advanced into the sub-segmental branches feeding the nodule [13]. A lobar technique was carried out in the case of a nodule fed by multiple arteries or when the selective/ superselective catheterization of the feeding artery was not technically feasible. All patients with PVT underwent a selective/superselective procedure.

After microcatheter placement, a mixture of epirubicin (Farmorubicin; Pfizer, Latina, Italy) and iodized oil (Lipiodol; Guerbet, Milan, Italy) was injected under fluoroscopic control, followed by embolization using Spongel (Gelitaspongel ${ }^{\circledR}$ ) particles until complete blockage of the tumor-feeding vessels was demonstrated. When the interventional radiologist was aware of being unable to achieve complete tumor embolization in only a single TACE session (for example, due to the use of the maximum dose of Epirubicin allowed), the treatment was split into two sessions approximately 1 month apart. In the present study, the two treatments were considered as only one treatment cycle. The mean chemotherapeutic agent dose administered per treatment was approximately $40 \mathrm{mg}$ of epirubicin (range, 20-75 mg) and the mean Lipiodol dose administered was approximately $8 \mathrm{~mL}$ (range, 4$15 \mathrm{~mL}$ ). Upon demonstration of a persistent viable tumor or intrahepatic distal recurrence at imaging follow-up, TACE was repeated "on demand".

\section{Assessment of tumor radiological response and follow-up} Patients underwent imaging assessment (quadriphasic CT or dynamic MRI) one month after TACE in order to evaluate the radiological response according to clinical practice. For the purpose of the study, all patients were evaluated according to the modified Response Evaluation Criteria in Solid Tumors (mRECIST) [14]. The response was considered complete (CR) when a dense homogeneous Lipiodol uptake with complete disappearance of any intratumoral enhancement was observed in the target lesion at CT scan or when no enhancement of the target nodule was observed at Dynamic MRI [14]. The other radiological responses were considered to be partial response (PR), progressive disease (PD) and stable disease (SD) according to the mRECIST criteria [14].

In all patients with a CR, a follow-up CT or MRI at 3-6 months was performed. A plain chest X-ray or chest CT were additionally utilized in the follow-up. For the assessment of overall survival, patient follow-up was carried out at the closure time of the study, at the time of death or at the last inpatient/outpatient clinical evaluation when no additional information was available (patients lost to follow-up). For the assessment of recurrence-free survival, patients were checked at the time of recurrence or death, at liver transplant (if performed) or at the last inpatient/outpatient clinical evaluation when no additional information was available (patients lost to follow-up).

\section{Statistical analysis}

Continuous variables were reported as medians and ranges. Comparisons among groups were calculated using nonparametric tests (Mann-Whitney and Wilcoxon). Categorical variables were compared using the $\chi^{2}$ test. All tests were considered significant at $\mathrm{P}<0.05$. Overall survival was defined as the time interval between TACE and death or the date of the last follow-up. Univariate analysis was carried out in order to identify the factors predicting survival. Survival curves were computed according to Kaplan-Meier methods and were compared using log rank tests. Variables with $\mathrm{P}<0.1$ in the univariate analysis were entered into a stepwise Cox regression model (conditional backward selection) to assess their impact as independent predictive factors. For patients who dropped out of the study, survival could be calculated by requesting the living status or time of death from the registry offices of the patients' hometowns, making them assessable for the survival analysis.

Analysis of the data was carried out using SPSS statistical analysis software (SPSS Inc., Chicago, Illinois, USA, 1999).

\section{Results}

Transarterial chemoembolization was the primary treatment after diagnosis of HCC in 148 patients with a single nodule of $\mathrm{HCC}$ who were not eligible for curative treatment (final study group) (Figure 1); their characteristics are reported in Tables 1 and 2. Transarterial chemoembolization was performed once in 80 patients (54\%), twice in 44 patients $(30 \%)$, three times in 17 patients $(11 \%)$ and 4 times in 7 patients (5\%). All patients with hepatitis B virus (HBV)-related cirrhosis received oral antiviral treatment as appropriate.

\section{Tumor response at 1 month}

A CR at one month was obtained in 95/148 (64\%) patients, a PR in 39 (26\%), SD in 1 patient and PD in 10 (7\%). Three patients were not evaluable (1 underwent radiofrequency as a complementary treatment after TACE and 2 received a liver transplant within 1 month after the procedure, before the CT).

At univariate analysis of pre-TACE clinical and tumoral variables to predict a complete radiological response (CR vs. non-CR), only tumor size was found to be a statistically significant predictor of complete response (Table 3), in particular, a tumor diameter $\leq 3 \mathrm{~cm}(P=0.017)$ and, more significantly, $\leq 5 \mathrm{~cm}$ (tumors within the Milan criteria, 
Table 1 Baseline demographic, clinical and tumor characteristics of the whole patient cohort before TACE treatment

\begin{tabular}{|c|c|}
\hline Variable & $\begin{array}{c}\text { Study population } \\
(\mathrm{n}=148)\end{array}$ \\
\hline Gender male, n (\%) & $104(70)$ \\
\hline Age, median (years) (range) & $64(36-84)$ \\
\hline \multicolumn{2}{|l|}{ Cause of disease, $\mathbf{n}(\%)$} \\
\hline HBV & $14(9)$ \\
\hline $\mathrm{HCV}$ & $85(57)$ \\
\hline Alcohol & $19(13)$ \\
\hline Multiple etiologies & $17(12)$ \\
\hline Unknown & $12(8)$ \\
\hline Other & $1(1)$ \\
\hline \multicolumn{2}{|l|}{ Lesion location, n (\%) } \\
\hline Right lobe & $110(74)$ \\
\hline Left lobe & $38(26)$ \\
\hline \multicolumn{2}{|l|}{ TACE Selectivity, n (\%) } \\
\hline Lobar & $10(7)$ \\
\hline Selective & $73(49)$ \\
\hline Superselective & $65(44)$ \\
\hline Tumor size, median $(\mathrm{cm})$ (range) & $3.0(0.8-15.0)$ \\
\hline Milan criteria within, $\mathrm{n}(\%)^{*}$ & $135(91)$ \\
\hline \multicolumn{2}{|l|}{ Portal vein thrombosis, $\mathrm{n}(\%)$} \\
\hline Absent & $131(88)$ \\
\hline Segmental bland thrombosis & $4(3)$ \\
\hline Lobar bland thrombosis & $13(9)$ \\
\hline Serum AFP, median (ng/mL) (range) & $14.5(1.0-39576.0)$ \\
\hline \multicolumn{2}{|l|}{ Ascites, n (\%) } \\
\hline Absent & $120(81)$ \\
\hline Slight - Moderate & $23(16)$ \\
\hline Severe - Refractory & $5(3)$ \\
\hline \multicolumn{2}{|l|}{ Encephalopathy, n (\%) } \\
\hline Absent & $145(98)$ \\
\hline Slight & $3(2)$ \\
\hline Serum total bilirubin, median $(\mathrm{mg} / \mathrm{dL})$ (range) & $1.34(0.30-10.67)$ \\
\hline Serum albumin, median ( $g / d L)$ (range) & $3.60(2.10-5.00)$ \\
\hline Serum INR, median (range) & $1.28(1.00-1.97)$ \\
\hline \multicolumn{2}{|l|}{ Hepatic function, $\mathrm{n}(\%)$} \\
\hline CPT-A & $92(62)$ \\
\hline CPT-B & $56(38)$ \\
\hline \multicolumn{2}{|l|}{ Performance status, $\mathrm{n}(\%)$} \\
\hline 0 & $133(90)$ \\
\hline 1 & $15(10)$ \\
\hline
\end{tabular}

Table 1 Baseline demographic, clinical and tumor characteristics of the whole patient cohort before TACE treatment (Continued)

\begin{tabular}{lc}
\hline BCLC stage, $\mathbf{n}(\%)$ & $16(11)$ \\
0 & $104(70)$ \\
A & $13(9)$ \\
B & $15(10)$ \\
MELD score, median (range) & $11(6-24)$ \\
\hline "patients with HCC $\leq 5 \mathrm{~cm}$. \\
Abbreviations: HBV hepatits B virus, HCV hepatitis C virus, TACE transarterial \\
chemoembolization, AFP Alpha-fetoprotein, INR international normalized ratio, \\
CPT Child-Pugh-Turcotte score, BCLC Barcelona Clinic Liver Cancer, MELD Model \\
for end stage liver disease.
\end{tabular}

$P=0.004)$. A trend towards higher pre-TACE values of alpha-fetoprotein (AFP) was found in incomplete responders.

\section{Local and distant recurrence after TACE}

Out of 95 patients achieving a CR, 61 (64\%) relapsed after a median time of 9 months (range 2-72), 28 (30\%) did not relapse after a median follow-up of 13.5 months (range 2-53) and 6 patients were not evaluable. Out of the 61 patients who relapsed, 23 patients (38\%) had local relapse after a median of 10 months (range 2-37), 23 (38\%) had distant intrahepatic relapse after a median of 8 months (range 2-72) and 15 (24\%) had both local and distant intrahepatic relapse after a median of 11 months (range 3-36). No patient developed extrahepatic spread before or concurrently with the detection of local or intrahepatic relapse. The overall recurrence rate in patients with complete response was $27 \%, 42 \%$ and $65 \%$ at 6,12 and 24 months, respectively.

\section{Impact of TACE on laboratory tests the day after the procedure}

A significant negative impact on liver function was observed the day after TACE treatment (Table 4). In particular, 56 (38\%) patients suffered a CPT increase $\geq 1$ point and 93 (63\%) patients suffered a Model for end stage liver disease (MELD) score increase $\geq 1$ point. Interestingly, a CPT and a MELD score increase $\geq 1$ were not related to a lobar TACE procedure ( $P=0.320$ and $P=1.000$, respectively).

The impact of TACE on the serum levels of albumin, bilirubin, the international normalized ratio (INR), creatinine and the MELD score the day after TACE is reported in Figure 2. More in detail, the median serum albumin values decreased from $3.60 \mathrm{mg} / \mathrm{dL}$ (range 2.105.00 ) to $3.50 \mathrm{mg} / \mathrm{dL}$ (range $2.10-4.50 ; P<0.001$ ) whereas the median serum values of bilirubin, the INR and the MELD score increased from $1.34 \mathrm{mg} / \mathrm{dL}$ (range 0.3010.67), 1.28 (range 1.00-1.97) and 11 (range 6-24) to $1.84 \mathrm{mg} / \mathrm{dL}$ (range 0.30-13.94; $P<0.001$ ), 1.33 (range 
Table 2 Clinical and tumor characteristics of the whole patient cohort before TACE treatment according to BCLC tumor stage

\begin{tabular}{|c|c|c|c|c|}
\hline Variable & BCLC-0 $(n=16)$ & BCLC-A $(n=104)$ & BCLC-B $(n=13)$ & BCLC-C $(n=15)$ \\
\hline 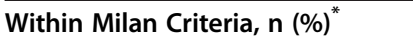 & $16(100)$ & $104(100)$ & 0 & $15(100)$ \\
\hline Tumor size, median $(\mathrm{cm})$ (range) & $1.3(1.0-1.9)$ & $3.0(0.8-5.0)$ & $6.0(5.1-15.0)$ & $3.0(1.0-4.8)$ \\
\hline \multicolumn{5}{|l|}{ Portal vein thrombosis, n (\%) } \\
\hline Absent & $14(88)$ & $94(90)$ & $11(85)$ & $12(80)$ \\
\hline Segmental bland thrombosis & 0 & $3(3)$ & 0 & $1(7)$ \\
\hline Lobar bland thrombosis & $2(12)$ & $7(7)$ & $2(15)$ & $2(13)$ \\
\hline \multicolumn{5}{|l|}{ Hepatic function pre TACE, n (\%) } \\
\hline CPT-A & $16(100)$ & $58(56)$ & $8(62)$ & $10(67)$ \\
\hline CPT-B & 0 & $46(44)$ & $5(38)$ & $5(33)$ \\
\hline \multicolumn{5}{|l|}{ Performance status pre TACE, $n$ (\%) } \\
\hline 0 & $16(100)$ & $104(100)$ & $13(100)$ & 0 \\
\hline 1 & 0 & 0 & 0 & 15 (100) \\
\hline
\end{tabular}

Percentages should be read as columns.

patients with $\mathrm{HCC} \leq 5 \mathrm{~cm}$.

Abbreviations: BCLC Barcelona Clinic Liver Cancer, TACE transarterial chemoembolization, CPT Child-Pugh-Turcotte score.

$1.00-2.00 ; P=0.003$ ) and 12 (range $7-24 ; P<0.001$ ), respectively. The median serum value of creatinine increased from $0.92 \mathrm{mg} / \mathrm{dL}$ (range $0.50-1.73$ ) to $0.97 \mathrm{mg} / \mathrm{dL}$ (0.57-2.27) but no statistical difference was observed $(P=0.823)$.

Patients with a CPT score increase $\geq 1$ point after the first TACE underwent more often one single rather than multiple TACE courses (70\% vs $30 \%$ of cases respectively, $P=0.006)$ in our routine clinical practice.

\section{Overall patient survival after TACE}

Out of the 148 patients who underwent TACE, 79 (53\%) died within the study period (January 2004 - May 2012) and 4 patients were lost to follow-up. The median overall follow-up of the entire study population was 44.0 months (95\% CI $=33.5-54.5)$ with 1-, 3- and 5-year survival rates of $89 \%, 61 \%$ and $42 \%$, respectively. If patients who underwent liver transplant (who generally were long-term survivors) were excluded (34 patients), the median overall follow-up decreased to 36.0 months $(95 \% \mathrm{CI}=24.6-47.4)$ with 1 -year, 3 -year and 5 -year survival rates of $85 \%, 50 \%$ and $26 \%$, respectively. The median survival of patients within the Milan criteria was 37 months, compared to 6 months of those beyond the Milan criteria.

At univariate analysis, tumor characteristics (and particularly tumor size), some liver function parameters and the achievement of a complete radiological response (Table 5) had a statistical impact on survival. Interestingly, an increase of $\geq 1$ point in the CPT or the MELD score the day after TACE was significantly associated with lower survival $(P=0.003)$ (Table 4). On the opposite the number of TACE was not associated with survival $(P=0.407)$. As expected, median survival was also influenced by the BCLC stage, but BCLC-B patients showed a lower median survival (6 months, $P=0.002$ ) with respect to BCLC 0-A (41 months) and BCLC-C (28 months) patients (the latter categorized as BCLC-C only on the basis of PS1 , but with tumor burden within the MC) (Figure 3). Furthermore, the presence of bland segmental or lobar PVT had no impact on overall survival but a slight impairment in PS (PS-1) did have an impact on prognosis since survival in PS-1 patients (BCLC-C) was worse than in that of PS-0 patients within the MC (BCLC 0-A). Nonetheless, the impact of PS on survival was minor with respect to the tumor burden since survival in PS-1 patients (BCLCC) was better than that in PS-0 patients beyond the MC (BCLC-B) (Tables 5 and 6, Figure 3).

All the variables in the univariate analysis with $P<0.1$ (Table 5) were entered into a Cox regression analysis, except for the CPT score and BCLC to avoid redundancy since the variables upon which they are built were already included in the analysis. After a conditional backward selection, tumor diameter beyond the Milan criteria $(P=$ 0.015 , OR $=3.0)$, lack of a complete radiological tumor response $(P=0.006, \mathrm{OR}=2.3)$, the presence of ascites before TACE $(P=0.021, \mathrm{OR}=2.3)$, AFP $\geq 14.5 \mathrm{ng} / \mathrm{mL}(P=0.007$, $\mathrm{OR}=2.1)$ and a MELD score increase $\geq 1$ point the day after TACE $(P=0.037, \mathrm{OR}=2.0)$ remained significant independent predictors of a worse survival.

\section{Discussion}

Curative treatment is recommended as the first-line treatment for patients with single HCC regardless of tumor diameter $[1,7]$. In clinical practice, however, patients with single tumors unfit for curative treatment are usually treated by TACE, based on clinical judgment. According to the current guidelines, TACE is the first line non-curative treatment for intermediate stage patients [1]. No evidence 
Table 3 Clinical and tumor characteristics of the whole patient cohort before TACE treatment according to tumor response

\begin{tabular}{|c|c|c|c|}
\hline Variable & $C R(n=95)$ & Non-CR $(n=50)$ & $P$ \\
\hline Gender male, n (\%) & & & 0.122 \\
\hline Male & $71(70)$ & $31(30)$ & \\
\hline Female & $24(56)$ & $19(44)$ & \\
\hline Age, median (years) (range) & $63(36-83)$ & $67.5(45-84)$ & 0.099 \\
\hline Cause of disease, $\mathbf{n}(\%)$ & & & 0.928 \\
\hline HBV & $7(50)$ & $7(50)$ & \\
\hline $\mathrm{HCV}$ & $54(66)$ & $28(34)$ & \\
\hline Alcohol & $15(79)$ & $4(21)$ & \\
\hline Multiple etiologies & $9(53)$ & $8(47)$ & \\
\hline Unknown & $9(75)$ & $8(25)$ & \\
\hline Other & $1(100)$ & $3(0)$ & \\
\hline Lesion location, n (\%) & & & 0.453 \\
\hline Right lobe & $72(67)$ & $35(33)$ & \\
\hline Left lobe & $23(61)$ & $15(39)$ & \\
\hline TACE selectivity, n (\%) & & & 0.992 \\
\hline Lobar & $5(50)$ & $5(50)$ & \\
\hline Selective & $45(63)$ & $26(37)$ & \\
\hline Superselective & $45(70)$ & $19(30)$ & \\
\hline Tumor size, $\mathrm{n}(\mathrm{cm})(\%)$ & & & 0.017 \\
\hline$\leq 3.0$ & $65(73)$ & $24(27)$ & \\
\hline$>3.0$ & $30(54)$ & $26(46)$ & \\
\hline Milan criteria, n (\%) & & & 0.004 \\
\hline Within $(\leq 5.0 \mathrm{~cm})$ & $92(69)$ & $41(31)$ & \\
\hline Beyond $(>5.0 \mathrm{~cm})$ & $3(25)$ & $9(75)$ & \\
\hline Portal vein thrombosis, $\mathrm{n}(\%)$ & & & 0.789 \\
\hline Absent & $83(65)$ & $45(35)$ & \\
\hline Bland thrombosis & $12(71)$ & $5(29)$ & \\
\hline Serum AFP, median ( $\mathrm{ng} / \mathrm{mL}$ ) (range) & $13.0(1.0-10000.0)$ & $21.0(2.0-39576.0)$ & 0.094 \\
\hline Ascites, n (\%) & & & 1.000 \\
\hline Absent & $77(66)$ & $40(34)$ & \\
\hline Present & $18(64)$ & $10(36)$ & \\
\hline Encephalopathy, n (\%) & & & 1.000 \\
\hline Absent & $93(66)$ & $49(34)$ & \\
\hline Slight & $2(67)$ & $1(33)$ & \\
\hline Serum total bilirubin, median (mg/dL) (range) & $1.39(0.30-7.56)$ & $1.24(0.35-7.72)$ & 0.594 \\
\hline Serum albumin, median (g/dL) (range) & $3.60(2.10-5.00)$ & $3.75(2.40-4.90)$ & 0.064 \\
\hline Serum INR, median (range) & $1.29(1.00-1.83)$ & $1.23(1.00-1.97)$ & 0.365 \\
\hline Hepatic function, n (\%) & & & 0.155 \\
\hline CPT-A & $55(61)$ & 35 (39) & \\
\hline CPT-B & $40(73)$ & $15(27)$ & \\
\hline
\end{tabular}

Performance status, $\mathbf{n}$ (\%)

$86(66)$
$9(60)$
$6(40)$


Table 3 Clinical and tumor characteristics of the whole patient cohort before TACE treatment according to tumor response (Continued)

\begin{tabular}{lcc}
\hline BCLC stage, $\mathbf{n}(\%)$ & & 0.077 \\
$0-\mathrm{A}$ & $83(70)$ & $35(30)$ \\
$\mathrm{B}$ & $3(25)$ & $6(75)$ \\
$\mathrm{C}$ & $9(60)$ & $11(6-24)$ \\
MELD score, median (range) & $12(7-19)$ & 0.637
\end{tabular}

Three patients not evaluable for tumor response were excluded from the analysis. Percentages should be read as rows.

Abbreviations: $C R$ complete response, $H B V$ hepatits $B$ virus, $H C V$ hepatitis $C$ virus, TACE transarterial chemoembolization, $A F P$ Alpha-fetoprotein, INR international normalized ratio, CPT Child-Pugh-Turcotte score, BCLC Barcelona Clinic Liver Cancer, MELD Model for end stage liver disease.

"P<0.05 are reported as bold numbers".

of a beneficial impact of TACE in patients with single HCC is reported in the guidelines since the trials upon which the guidelines are built [15], for the most part, included patients with multiple nodules of HCC. Accordingly, TACE is frequently performed outside the current treatment guidelines in a considerable percentage of patients with a single nodule, according to a "stage migration strategy" [16].

Only a few studies have evaluated the efficacy of TACE in patients with a single nodule $[5,17,18]$ and a valid comparison with previous data reported in the literature is very difficult, due to the different criteria used for the evaluation of tumor response, TACE procedure, the selectivity of technique and the expertise of the radiological center. This fact led to the investigation of the overall survival and clinical determinants of survival in patients with a single nodule who represent approximately half $(45 \%)$ of the total cohort of patients who underwent a first TACE cycle in our Interventional Radiology Unit (156/ 344) (Figure 1). This number is fully comparable to a very large Japanese series in which patients with single tumors were $46 \%$ of those who underwent TACE [5], and some

Table 4 Liver function parameters of the whole patient cohort before and one day after TACE procedure

\begin{tabular}{|c|c|c|c|}
\hline Variable & Pre-TACE & Post-TACE & $P$ \\
\hline Ascites, n (\%) & & & 0.564 \\
\hline Absent & $120(81)$ & $116(78)$ & \\
\hline Present & $28(19)$ & $32(22)$ & \\
\hline Encephalopathy, n (\%) & & & 1.000 \\
\hline Absent & $145(98)$ & $145(98)$ & \\
\hline Slight & $3(2)$ & $3(2)$ & \\
\hline Serum total bilirubin, median (mg/dL) (range) & $1.34(0.30-10.67)$ & $1.85(0.30-13.94)$ & $<0.001$ \\
\hline Serum albumin, median (g/dL) (range) & $3.60(2.10-5.00)$ & $3.50(2.10-4.50)$ & $<0.001$ \\
\hline Serum creatinine, median (range) & $0.92(0.50-1.73)$ & $0.97(0.57-2.27)$ & 0.823 \\
\hline Hepatic function, n (\%) & & & 0.010 \\
\hline CPT-A & $92(62)$ & $81(55)$ & \\
\hline CPT-B & $56(38)$ & $61(41)$ & \\
\hline CPT-C & 0 & $6(4)$ & \\
\hline Hepatic function, n (\%) & & & 0.054 \\
\hline CPT-A5 & $65(44)$ & $53(36)$ & \\
\hline CPT-A6 & $27(18)$ & $27(18)$ & \\
\hline CPT-B7 & $28(19)$ & $26(18)$ & \\
\hline CPT-B8 & $21(14)$ & $25(17)$ & \\
\hline CPT-B9 & $7(5)$ & $11(7)$ & \\
\hline CPT-C10 & 0 & $6(4)$ & \\
\hline Serum INR, median (range) & $1.28(1.00-1.97)$ & $1.33(1.00-2.00)$ & 0.003 \\
\hline MELD score, median (range) & $11(6-24)$ & $12(7-24)$ & $<0.001$ \\
\hline
\end{tabular}

Percentages should be read as columns.

Abbreviations: CPT Child-Pugh-Turcotte score, INR international normalized ratio, MELD Model for end stage liver disease.

$\mathrm{P}<0.05$ are reported as bold numbers. 


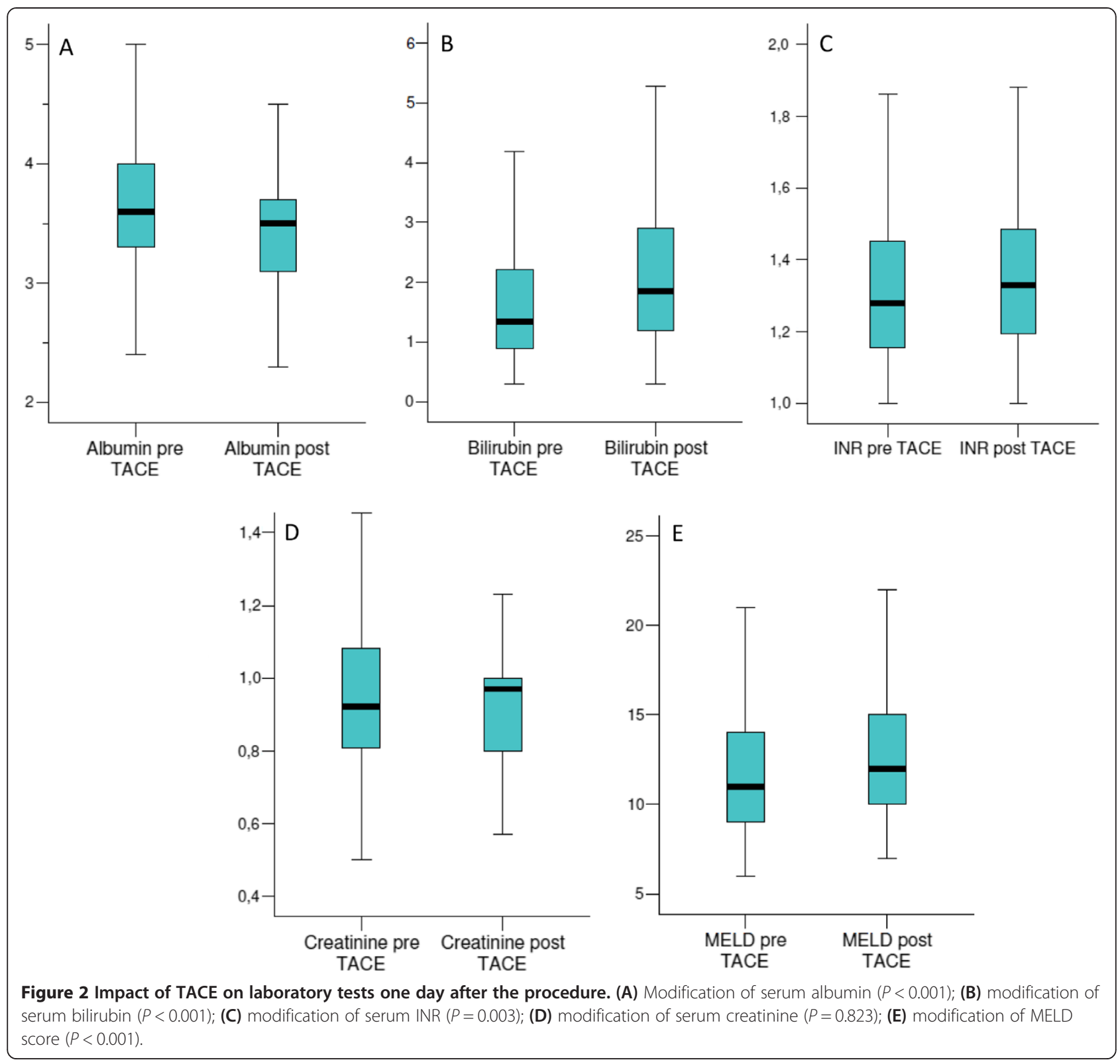

other studies $[14,19]$ which showed high heterogeneity of patients routinely undergoing TACE, including 35-50\% of patients with single tumors, even those $<5 \mathrm{~cm}$. Furthermore, the vast majority of the studies investigating the efficacy of TACE excluded patients with advanced liver disease, PVT and impaired PS; therefore, there was also no evidence of the impact of TACE in those categories of patients [20]. The allocation policy and the impact of TACE in patients with impaired liver function (namely CPT-B patients) has already been described [21] and, in the present study, the aim was to evaluate the impact of bland PVT and slight impairment of PS on overall survival after TACE.
The median overall survival of the entire patient population, after the exclusion of patients who underwent LT who were generally long term survivors, was 36.0 months with 1-, 3- and 5-years survival rates of $85 \%, 50 \%$ and $26 \%$, respectively. These data are slightly lower than those observed in a large Japanese series [5] reporting 1 -, 3 - and 5-years survival rates of $91 \%, 66 \%$ and $53 \%$, respectively in patients treated with TACE for a single nodule of HCC (even though no information regarding possible subsequent LT was reported). As expected, when comparing these results with those reported in the metanalysis of Llovet et al. (median survival of 20 months in patients who underwent TACE) in which 
Table 5 Univariate survival analysis

\begin{tabular}{|c|c|c|c|c|c|}
\hline \multirow[t]{2}{*}{ Variable } & \multicolumn{3}{|c|}{ Survival (\%) } & \multirow{2}{*}{$\begin{array}{c}\text { Median } \\
\text { survival ( } 95 \% \text { C.I.) }\end{array}$} & \multirow[t]{2}{*}{$P$} \\
\hline & $1-y r$ & $3-y r$ & $\overline{5-y r}$ & & \\
\hline \multicolumn{6}{|l|}{ Gender } \\
\hline Male & 84 & 45 & 29 & $26.0(16.7-35.3)$ & \multirow{2}{*}{0.975} \\
\hline Female & 88 & 63 & 20 & $41.0(34.9-47.1)$ & \\
\hline
\end{tabular}

Age, yr

$$
<64
$$$$
\geq 64
$$

\section{Cause of disease}

Alcohol

Non alcohol

81

86

TACE selectivity

Lobar

Selective

Superselective

Milan criteria

Within $(\leq 5.0 \mathrm{~cm})$

Beyond $(>5.0 \mathrm{~cm})$

Portal vein thrombosis

Absent

Bland thrombosis

AFP, $\mathrm{ng} / \mathrm{mL}$

$$
\begin{aligned}
& <14.5 \\
& \geq 14.5
\end{aligned}
$$

Ascites

$$
\text { Absent }
$$

Present

Serum total bilirubin, $\mathrm{mg} / \mathrm{dL}$

$$
<1.34
$$$$
\geq 1.34
$$

Serum albumin, $\mathrm{g} / \mathrm{dL}$

$$
\begin{aligned}
& <3.60 \\
& \geq 3.60
\end{aligned}
$$

\section{Serum INR}

$$
\begin{aligned}
& <1.28 \\
& \geq 1.28
\end{aligned}
$$

Hepatic function

CPT-A

CPT-B

Hepatic function. Pts Milan in patients

$$
\text { CPT-A }
$$$$
\text { CPT-B }
$$

$$
97
$$

\section{Performance status}

$$
0
$$

35

59

\section{6}

26

\section{8}

56

\section{1}

$24.0(21.5-26.5)$

$40.0(36.2-43.8)$

$24.0(22.5-25.5)$

$40.0(33.0-47.0)$

$44.0(0-104.8)$

$36.0(25.8-46.2)$

0.823

$26.0(10.2-41.8)$

$37.0(30.2-43.8)$

$6.0(0-17.3)$

0.003

$36.0(24.0-48.0)$

$36.0(4.6-67.4)$

$41.0(23.0-59.0)$

$25.0(19.5-30.5)$

$37.0(29.0-45.0)$

$15.0(3.0-27.0)$

0.013

$41.0(36.6-45.4)$

$23.0(18.1-27.9)$

0.026

$24.0(18.3-29.6)$

$40.0(32.4-47.6)$

0.340

$40.0(34.5-45.5)$

$25.0(18.8-31.2)$

$40.0(36.1-43.9)$

$21.0(15.3-26.7)$

$41.0(37.2-44.8)$

$21.0(14.3-27.7)$

0.053

$36.0(24.7-47.3)$

$28.0(11.2-44.7)$ 
Table 5 Univariate survival analysis (Continued)

\begin{tabular}{|c|c|c|c|c|c|}
\hline \multicolumn{6}{|l|}{ PS. Patients Milan In } \\
\hline 0 & 91 & 55 & 31 & $41.0(31.5-50.5)$ & \multirow{2}{*}{0.025} \\
\hline 1 & 83 & 50 & 0 & $28.0(11.2-44.8)$ & \\
\hline \multicolumn{6}{|l|}{ BCLC stage } \\
\hline $0-A$ & 91 & 55 & 31 & $41.0(31.5-50.5)$ & \multirow{3}{*}{0.002} \\
\hline B & 46 & 18 & 10 & $6.0(0-17.3)$ & \\
\hline C & 83 & 47 & 0 & $28.0(11.2-44.8)$ & \\
\hline \multicolumn{6}{|l|}{ MELD score } \\
\hline$<11$ & 92 & 61 & 34 & $41.0(27.0-55.0)$ & \multirow{2}{*}{0.060} \\
\hline$\geq 11$ & 78 & 41 & 18 & $25.0(21.5-28.5)$ & \\
\hline \multicolumn{6}{|l|}{ Child-Pugh increase post-TACE } \\
\hline Absent & 92 & 60 & 35 & $41.0(33.6-48.3)$ & \multirow{2}{*}{0.003} \\
\hline$\geq 1$ point & 83 & 35 & 14 & $22.0(10.3-33.6)$ & \\
\hline \multicolumn{6}{|l|}{ MELD increase post-TACE } \\
\hline Absent & 94 & 39 & 44 & $44.0(24.5-63.4)$ & \multirow{2}{*}{0.003} \\
\hline$\geq 1$ point & 80 & 43 & 17 & $25.0(17.9-32.0)$ & \\
\hline \multicolumn{6}{|l|}{ Tumor response } \\
\hline$C R$ & 92 & 54 & 30 & $37.0(25.4-48.6)$ & \multirow{2}{*}{0.048} \\
\hline Non-CR & 72 & 45 & 17 & $28.0(17.8-38.2)$ & \\
\hline \multicolumn{6}{|l|}{ Recurrence } \\
\hline Absent & 88 & 57 & 57 & $36.0(12.1-59.9)$ & \multirow{2}{*}{0.817} \\
\hline Present & 94 & 72 & 55 & $40.0(26.9-53.1)$ & \\
\hline \multicolumn{6}{|l|}{ Recurrence type } \\
\hline Local & 95 & 63 & 32 & $42.0(31.4-52.6)$ & \multirow{3}{*}{0.312} \\
\hline Distant intrahepatic & 100 & 53 & 39 & $44.0(9.5-78.5)$ & \\
\hline Local + distant intrahepatic & 82 & 45 & 11 & $31.0(12.1-49.9)$ & \\
\hline
\end{tabular}

Patients submitted to liver transplant (LT) were excluded from the analysis (34 patients). The assessment of tumor response was considered at 1 month after TACE. In the analysis of survival according to tumor response also patients not evaluable were excluded from the analysis.

Abbreviations: HCV hepatitis C virus, TACE transarterial chemoembolization, AFP Alpha-fetoprotein, INR international normalized ratio, CPT Child-Pugh-Turcotte score, $B C L C$ Barcelona Clinic Liver Cancer, MELD Model for end stage liver disease, $C R$ complete response, $P R$ partial response, $P D$ progressive disease, $P S=P e r f o r m a n c e$ Statsus, BCLC Barcelona Clinic Liver Cancer.

$\mathrm{P}<0.05$ are reported as bold numbers.

the vast majority of patients had multinodular HCC [15], the median overall survival was considerably higher despite the large presence of CPT-B patients in our series. On the basis of survival analysis, TACE treatment indeed represents a valid therapeutic option for patients with single $\mathrm{HCC}$ who are not eligible for curative treatment, as has also been shown by recent series of BCLC-A patients from Barcelona and from Pisa [17,22]. Such data also supported the use of the stage migration policy from the early to the intermediate HCC stage.

When assessing the clinical predictors of survival, tumor diameter $>3 \mathrm{~cm}$, and particularly $>5 \mathrm{~cm}$ (beyond the $\mathrm{MC}$ ), lack of complete radiological tumor response, AFP $\geq 14.5 \mathrm{ng} / \mathrm{mL}$, the presence of ascites before TACE and a MELD increase $\geq 1$ point the day after TACE were found to be independently associated with shorter survival at multivariate analysis. These data are in agreement with the fact that life expectancy depends not only upon tumor treatment efficacy, but also on the underlying severity of liver disease and patients with worsening hepatic function after TACE; with a MELD score increase $\geq 1$ point, they are at risk of liver failure.

The presence of bland PVT in patients with HCC represents a challenging therapeutic issue. In recent decades, some authors [23] have considered the presence of PVT to be a contraindication for TACE due to the risk of liver function deterioration and hepatic infarct [24] but patients with PVT may not present technical and safety contraindications to TACE if a selective/superselective procedure is performed [20,25]. In fact, more recent studies have demonstrated that TACE could be a safe treatment option for HCC patients with PV occlusion especially when performed in a selective manner [26], and that TACE could have a survival benefit over conservative treatment 


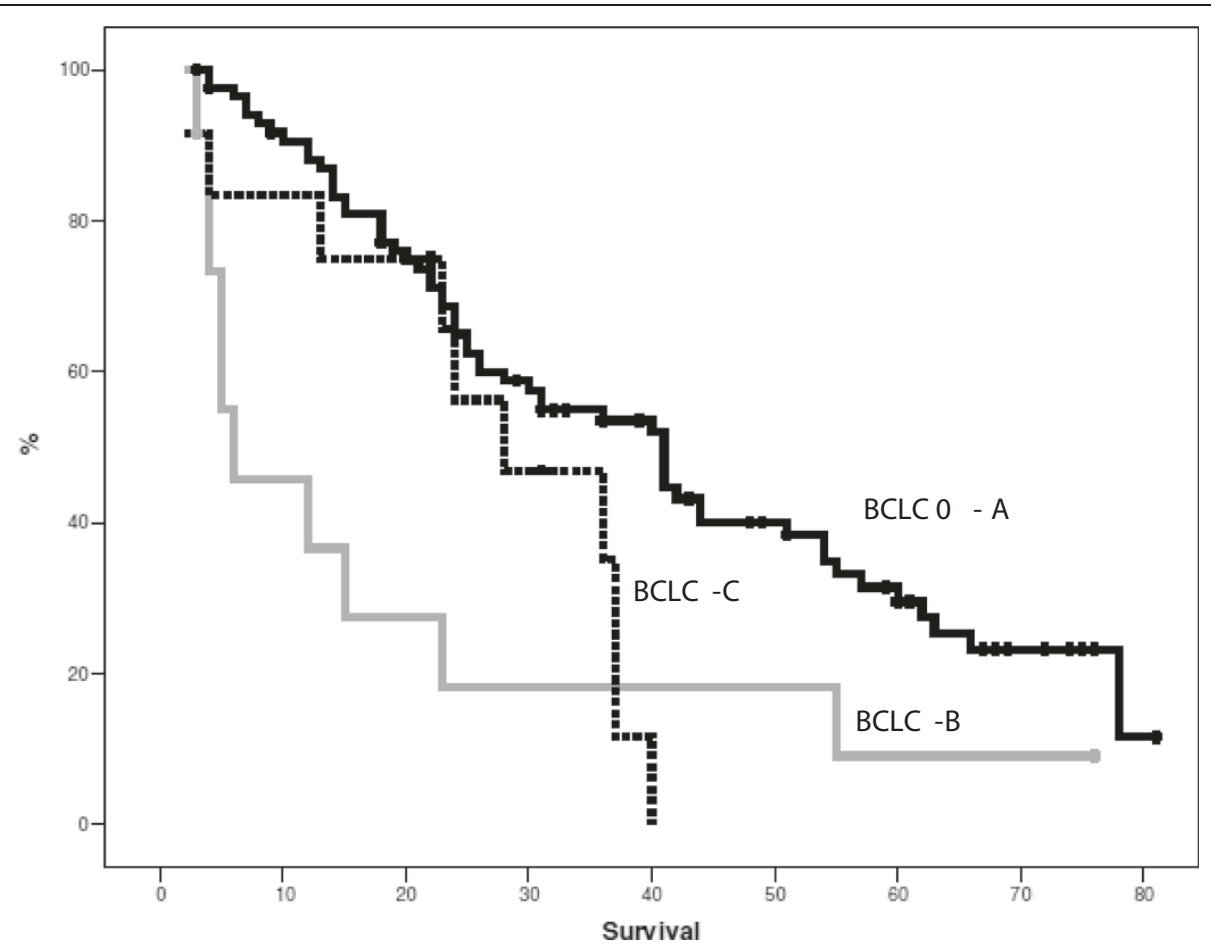

Figure 3 Overall survival according to BCLC tumor stage.

Table 6 Liver function parameters of patients with tumor burden within Milan criteria $(n=135)$ on the basis of performance status

\begin{tabular}{|c|c|c|c|}
\hline Variable & PS-0 $(n=120)$ & PS-1 $(n=15)$ & $P$ \\
\hline Ascites, n (\%) & & & 1.000 \\
\hline Absent & $98(82)$ & $12(80)$ & \\
\hline Present & $22(18)$ & $3(20)$ & \\
\hline Encephalopathy, n (\%) & & & 0.300 \\
\hline Absent & $118(98)$ & $14(93)$ & \\
\hline Slight & $2(2)$ & $1(7)$ & \\
\hline Serum total bilirubin, median ( $\mathrm{mg} / \mathrm{dL})$ (range) & $1.39(0.30-10.67)$ & $1.23(0.53-7.72)$ & 0.817 \\
\hline Serum albumin, median ( $g / d L)$ (range) & $3.60(2.40-5.00)$ & $3.60(2.80-4.90)$ & 0.596 \\
\hline Serum INR, median (range) & $1.28(1.00-1.97)$ & $1.23(1-1.86)$ & 0.535 \\
\hline Serum creatinine, median (range) & $0.92(0.50-1.73)$ & $0.78(0.65-1.66)$ & 0.115 \\
\hline Hepatic function, n (\%) & & & 0.784 \\
\hline CPT-A & $74(62)$ & $10(67)$ & \\
\hline CPT-B & $46(38)$ & $5(33)$ & \\
\hline Hepatic function, n (\%) & & & 0.655 \\
\hline CPT-A5 & $54(45)$ & $6(40)$ & \\
\hline CPT-A6 & $20(17)$ & $4(27)$ & \\
\hline CPT-B7 & $22(18)$ & $1(7)$ & \\
\hline CPT-B8 & $19(16)$ & $2(13)$ & \\
\hline CPT-B9 & $5(4)$ & $2 n$ & \\
\hline
\end{tabular}


$[27,28]$. In our Hospital, patients with bland thrombosis are candidates for TACE if they have preserved liver function, limited tumor burden, contraindications to other treatment and a selective approach is feasible. Interestingly, despite the limited number of patients with bland PVT $(n=17)$ who underwent TACE, our results showed that the presence of bland PVT, either lobar or segmental, has no negative impact on overall survival when TACE is performed with a selective or superselective approach.

The BCLC staging system includes the ECOG PS [12] evaluation regarding the assessment of tumor stage. In patients with $\mathrm{HCC}$, the classic determination of PS is not able to differentiate between cancer- or cirrhosisrelated symptoms [16] and the subjective assessment of "how the patient feels" can be related to cirrhosis as well as to cancer. In our study population, 15 patients with PS-1 were formally classified to be in the advanced stage (BCLC-C) (Table 2) but, since the tumor diameter was $\leq 5 \mathrm{~cm}$, the likelihood of having cancer-related symptoms could be considered very low. Accordingly, these patients in BCLC-C had a significant and theoretically paradoxical better survival (28 months) than patients in the BCLC-B stage (6 months), as all the latter had large tumors (diameter $>5 \mathrm{~cm}$ ) (Tables 2, 5). It could be speculated that, in case of symptoms of uncertain tumor relation, the tumor burden should be considered the driving force for treatment allocation. On the other hand, considering patients with the same tumor burden (within the MC), PS-1, and consequently the same liver function, this certainly impacts survival so that BCLC-C patients (PS-1) had significantly worse survival with respect to BCLC 0-A patients (PS-0) (Figure 3).

To the best of our knowledge, the only data on tumor radiological response of conventional TACE in patients with single unresectable $\mathrm{HCC}$ is that of Malagari et al. [18]. Our study showed notably higher objective response rates $(\mathrm{CR}+\mathrm{PR})$ of $90 \%$ vs. $59.6 \%$ and superior rates of CR (64\%) and PR (26\%) (Table 3) as compared to the 4.8\% CR and $54.8 \%$ PR reported by Malagari. Our data appeared consistent with those reporting per-nodule TACE efficacy (mimicking patients with a single nodule) [29] where similar CR and PR rates were reported (64\% and $36 \%$, respectively) and tumor diameter $\leq 5 \mathrm{~cm}$ was again found to be a statistical predictor of complete response [29].

We acknowledge that the response rate in our study might be overestimated since the assessment of radiological response was usually made with $\mathrm{CT}$, which may underestimate the residual tumor due to the interference of Lipiodol [13]. The availability of MRI was not sufficient to offer this technique as a standard procedure after TACE to all patients. Nevertheless, our data are of current interest since, despite the introduction of TACE using drug-eluting beads [30,31], clinical trials comparing TACE with drug-eluting beads and conventional TACE did not show significant differences in tumor response and overall survival $[19,32]$ and, nowadays, conventional TACE is still for the most part used.

A number of studies have demonstrated that the repetition of TACE increases tumor response and prolongs survival [16], but it is necessary to select the best TACE candidates who could benefit from treatment and eventually subsequent cancer retreatment in order to avoid overtreatment and detrimental effects on liver function. The issue of proper patient selection for retreatment after TACE has become more stringent in recent years due to the availability of alternative treatments such as sorafenib [33], and radioembolization [24]. To this end, the worsening of laboratory tests 24 hours after treatment was evaluated and a significant modification in serum albumin, bilirubin, the INR and the MELD score after TACE treatment was documented (Figure 2). As expected, it was also found that patients with a CPT score increase $\geq 1$ point were more likely to undergo a single TACE cycle vs. multiple cycles $(70 \%$ vs. $30 \%, P=0.006)$ Furthermore, both a CPT and a MELD score $\geq 1$ point increase were found to be associated with a significantly worse prognosis (Table 4). Such findings do not affect the initial choice of recommending TACE, but seem to alert clinicians to consider the risk that patients will be no more candidate for future repeated TACE in case of early CPT score worsening after the procedure, deserving an even more careful assessment of treatment strategy.

\section{Conclusion}

In conclusion, our results showed TACE to be an effective curative treatment in patients with a single nodule of HCC who were not eligible for curative treatment, supporting the strategy of stage migration for early single HCC. Bland PVT has no major impact on survival and a slight impairment of PS (PS-1) most likely attributable to cirrhosis in patients with a tumor burden within the Milan criteria should not preclude the use of TACE. This confirmed the fundamental role of individual clinical judgment in the treatment of HCC.

\author{
Competing interests \\ Terzi E: none. \\ Piscaglia F: has received fees as a consultant and/or speaker from Bracco, \\ Bayer, GE Healthcare, Siemens \\ Forlani L: none. \\ Mosconi C: none. \\ Renzulli M: none. \\ Bolondi L: has received fees as a consultant and/or speaker from Bracco, \\ Bayer, Roche, Bristol-Meyer-Squibb \\ Golfieri R: has received fees as a consultant and/or speaker from Bayer, Sirtex
}

Authors' contributions

ET made a substantial contribution in the acquisition, analysis and

interpretation of data. She helped in drafting the paper. FP made a 
substantial contribution to research design, analysis and interpretation of data. He helped in drafting the paper, revising it critically and gave approval of the submitted and final versions. FF made a substantial contribution in the acquisition of data. CM made a substantial contribution in the analysis and interpretation of data. MR made a substantial contribution in the acquisition and analysis of data. LB: revised the paper critically and gave approval of the submitted and final versions. RG: contributed to the analysis and interpretation of the data, revised the paper critically and gave approval of the submitted and final versions. All authors read and approved the final manuscript.

\section{Acknowledgements}

No specific funding was received connected to the present work.

\section{Author details}

${ }^{1}$ Division of Internal Medicine, Department of Digestive Disease and Internal Medicine, Sant'Orsola-Malpighi Hospital, University of Bologna, Via Albertoni 15, 40138 Bologna, Italy. ${ }^{2}$ Radiology Unit, Department of Digestive Disease and Internal Medicine, Sant'Orsola-Malpighi General and University Hospital, Bologna, Italy.

Received: 1 November 2013 Accepted: 6 August 2014 Published: 19 August 2014

\section{References}

1. European Association For The Study Of The Liver, European Organisation For Research And Treatment Of Cancer: EASL-EORTC clinical practice guidelines: management of hepatocellular carcinoma. J Hepatol 2012, 56:908-943.

2. Mazzaferro V, Regalia E, Doci R, Andreola S, Pulvirenti A, Bozzetti F, Montalto F, Ammatuna M, Morabito A, Gennari L: Liver transplantation for the treatment of small hepatocellular carcinomas in patients with cirrhosis. N Engl J Med 1996, 334:693-699.

3. Cescon M, Vetrone G, Grazi GL, Ramacciato G, Ercolani G, Ravaioli M, Del Gaudio M, Pinna AD: Trends in perioperative outcome after hepatic resection: analysis of 1500 consecutive unselected cases over 20 years. Ann Surg 2009, 249:995-1002.

4. Piscaglia F, Camaggi V, Ravaioli M, Grazi GL, Zanello M, Leoni S, Ballardini G, Cavrini G, Pinna AD, Bolondi L: A new priority policy for patients with hepatocellular carcinoma awaiting liver transplantation within the model for end-stage liver disease system. Liver Transp/ 2007, 13:857-866.

5. Takayasu K, Arii S, Kudo M, Ichida T, Matsui O, Izumi N, Matsuyama Y, Sakamoto M, Nakashima O, Ku Y, Kokudo N, Makuuchi M: Superselective transarterial chemoembolization for hepatocellular carcinoma. Validation of treatment algorithm proposed by Japanese guidelines. J Hepatol 2012, 56:886-892.

6. Terzi E, Golfieri R, Piscaglia F, Galassi M, Dazzi A, Leoni S, Giampalma E, Renzulli M, Bolondi L: Response rate and clinical outcome of HCC after first and repeated cTACE performed "on demand". J Hepatol 2012, 57:1258-1267.

7. Bruix J, Sherman M: Management of hepatocellular carcinoma. Hepatology 2005, 42:1208-1236.

8. Bruix J, Sherman M, Llovet JM, Beaugrand M, Lencioni R, Burroughs AK, Christensen E, Pagliaro L, Colombo M, Rodés J: EASL Panel of Experts on HCC. Clinical management of hepatocellular carcinoma. Conclusions of the Barcelona-2000 EASL conference. European Association for the Study of the Liver. J Hepatol 2001, 35:421-430.

9. Piscaglia F, Gianstefani A, Ravaioli M, Golfieri R, Cappelli A, Giampalma E, Sagrini E, Imbriaco G, Pinna AD, Bolondi L, Bologna Liver Transplant Group: Criteria for diagnosing benign portal vein thrombosis in the assessment of patients with cirrhosis and hepatocellular carcinoma for liver transplantation. Liver Transp/ 2010, 16:658-667.

10. Llovet JM, Bru C, Bruix J: Prognosis of hepatocellular carcinoma: the BCLC staging classification. Semin Liver Dis 1999, 19:329-338.

11. Position paper of the Italian Association for the Study of the Liver (AISF): The multidisciplinary clinical approach to hepatocellular carcinoma. Dig Liver Dis 2013, 45:712-723.

12. Sorensen JB, Klee M, Palshof T, Hansen HH: Performance status assessment in cancer patients. An inter-observer variability study. Br J Cancer 1993, $67: 773-775$
13. Golfieri R, Cappelli A, Cucchetti A, Piscaglia F, Carpenzano M, Peri E, Ravaioli M, D’Errico-Grigioni A, Pinna AD, Bolondi L: Efficacy of selective transarterial chemoembolization in inducing tumor necrosis in small $(<5 \mathrm{~cm})$ hepatocellular carcinomas. Hepatology 2011, 53:1580-1589.

14. Lencioni R, Llovet JM: Modified RECIST (mRECIST) assessment for hepatocellular carcinoma. Semin Liver Dis 2010, 30:52-60.

15. Llovet JM, Bruix J: Systematic review of randomized trials for unresectable hepatocellular carcinoma: Chemoembolization improves survival. Hepatology 2003, 37:429-442.

16. Bolondi L, Burroughs A, Dufour JF, Galle PR, Mazzaferro V, Piscaglia F, Raoul JL, Sangro B: Heterogeneity of patients with intermediate (BCLC B) hepatocellular carcinoma: proposal for a subclassification to facilitate treatment decisions. Semin Liver Dis 2012, 32:348-359.

17. Bargellini I, Sacco R, Bozzi E, Bertini M, Ginanni B, Romano A, Cicorelli A, Tumino E, Federici G, Cioni R, Metrangolo S, Bertoni M, Bresci G, Parisi G, Altomare E, Capria A, Bartolozzi C: Transarterial chemoembolization in very early and early-stage hepatocellular carcinoma patients excluded from curative treatment: a prospective cohort study. Eur J Radiol 2012, 81:1173-1178.

18. Malagari K, Chatzimichael K, Alexopoulou E, Kelekis A, Hall B, Dourakis S, Delis S, Gouliamos A, Kelekis D: Transarterial chemoembolization of unresectable hepatocellular carcinoma with drug eluting beads: results of an open-label study of 62 patients. Cardiovasc Intervent Radiol 2008, 31:269-280.

19. Sangro B, D'Avola D, Inarrairaegui M, Prieto J: Transarterial therapies for hepatocellular carcinoma. Expert Opin Pharmacother 2011, 12:1057-1073.

20. Marelli L, Stigliano R, Triantos C, Senzolo M, Cholongitas E, Davies N, Tibballs J, Meyer T, Patch DW, Burroughs AK: Transarterial therapy for hepatocellular carcinoma: which technique is more effective? A systematic review of cohort and randomized studies. Cardiovasc Intervent Radiol 2007, 30:6-25.

21. Piscaglia F, Terzi E, Cucchetti A, Trimarchi C, Granito A, Leoni S, Marinelli S, Pini P, Bolondi L: Treatment of hepatocellular carcinoma in Child-Pugh B patients. Dig Liver Dis 2013, 45:852-858.

22. Burrel M, Reig M, Forner A, Barrufet M, de Lope CR, Tremosini S, Ayuso C, Llovet JM, Real MI, Bruix J: Survival of patients with hepatocellular carcinoma treated by transarterial chemoembolisation (TACE) using Drug Eluting Beads. Implications for clinical practice and trial design. J Hepatol 2012, 56:1330-1335.

23. Chung JW, Park JH, Han JK, Choi BI, Han MC, Lee HS, Kim CY: Hepatic tumors: predisposing factors for complications of transcatheter oily chemoembolization. Radiology 1996, 198:33-40.

24. Kulik LM, Carr BI, Mulcahy MF, Lewandowski RJ, Atassi B, Ryu RK, Sato KT, Benson A 3rd, Nemcek AA Jr, Gates VL, Abecassis M, Omary RA, Salem R: Safety and efficacy of 90Y radiotherapy for hepatocellular carcinoma with and without portal vein thrombosis. Hepatology 2008, 47:71-81.

25. Pentecost MJ, Daniels JR, Teitelbaum GP, Stanley P: Hepatic chemoembolization: safety with portal vein thrombosis. J Vasc Interv Radiol 1993, 4:347-351.

26. Kim JH, Yoon HK, Kim SY, Kim KM, Ko GY, Gwon DI, Sung KB: Transcatheter arterial chemoembolization vs. chemoinfusion for unresectable hepatocellular carcinoma in patients with major portal vein thrombosis. Aliment Pharmacol Ther 2009, 29:1291-1298.

27. Georgiades CS, Hong K, D'Angelo M, Geschwind JF: Safety and efficacy of transarterial chemoembolization in patients with unresectable hepatocellular carcinoma and portal vein thrombosis. J Vasc Interv Radiol 2005, 16:1653-1659.

28. Luo J, Guo RP, Lai EC, Zhang YJ, Lau WY, Chen MS, Shi M: Transarterial chemoembolization for unresectable hepatocellular carcinoma with portal vein tumor thrombosis: a prospective comparative study. Ann Surg Oncol 2011, 18:413-420.

29. Golfieri R, Renzulli M, Mosconi C, Forlani L, Giampalma E, Piscaglia F, Trevisani F, Bolondi L, Bologna Liver Oncology Group (BLOG): Hepatocellular carcinoma responding to superselective transarterial chemoembolization: an issue of nodule dimension? J Vasc Interv Radiol 2013, 24:509-517.

30. Raoul JL, Sangro B, Forner A, Mazzaferro V, Piscaglia F, Bolondi L, Lencioni R: Evolving strategies for the management of intermediate-stage hepatocellular carcinoma: available evidence and expert opinion on the use of transarterial chemoembolization. Cancer Treat Rev 2011, 37:212-220.

31. Lencioni R: Chemoembolization in patients with hepatocellular carcinoma. Liver Cancer 2012, 1:41-50. 
32. Malagari K, Pomoni M, Kelekis A, Pomoni A, Dourakis S, Spyridopoulos T, Moschouris H, Emmanouil E, Rizos S, Kelekis D: Prospective randomized comparison of chemoembolization with doxorubicin-eluting beads and bland embolization with BeadBlock for hepatocellular carcinoma. Cardiovasc Intervent Radiol 2010, 33:541-551.

33. Llovet JM, Ricci S, Mazzaferro V, Hilgard P, Gane E, Blanc JF, de Oliveira AC, Santoro A, Raoul JL, Forner A, Schwartz M, Porta C, Zeuzem S, Bolondi L, Greten TF, Galle PR, Seitz JF, Borbath I, Häussinger D, Giannaris T, Shan M, Moscovici M, Voliotis D, Bruix J, SHARP Investigators Study Group: Sorafenib in advanced hepatocellular carcinoma. N Engl J Med 2008, 359:378-390.

doi:10.1186/1471-2407-14-601

Cite this article as: Terzi et al.: TACE performed in patients with a single nodule of Hepatocellular Carcinoma. BMC Cancer 2014 14:601.

\section{Submit your next manuscript to BioMed Central and take full advantage of:}

- Convenient online submission

- Thorough peer review

- No space constraints or color figure charges

- Immediate publication on acceptance

- Inclusion in PubMed, CAS, Scopus and Google Scholar

- Research which is freely available for redistribution 